\title{
Antimalarial medicine diversion: stock-outs and other public health problems
}

This article was published in the following Dove Press journal:

Research and Reports in Tropical Medicine

8 September 2010

Number of times this article has been viewed

\section{Roger Bate ${ }^{1,2}$ \\ Kimberly Hess ${ }^{2}$ \\ Lorraine Mooney ${ }^{3}$}

'American Enterprise Institute, Washington, D.C., USA; ${ }^{2}$ Africa Fighting Malaria, Washington, D.C., USA; ${ }^{3}$ Africa Fighting Malaria,

Cambridge, UK
Correspondence: Roger Bate

II 50 Seventeenth Street, N.W.,

Washington, D.C. 20036, USA

Tel +l 2028286029

Fax +I 2028627177

Email rbate@aei.org
Background: Antimalarial medicine diversion has been seen across numerous African markets and can lead to serious stock-outs in the public sector, which can be dangerous to countries with high burdens of disease. This study discusses the numbers of diverted antimalarial medicines from several samplings in Africa.

Methods: A total of 894 samples of antimalarial medicines were covertly purchased from private pharmacies in 11 African cities from late 2007 to early 2010. All medicine packages were visually inspected for correctness, in line with the protocol established by the Global Pharma Health Fund e.V. Minilab ${ }^{\circledR}$, as well as for signs of diversion.

Results: Overall, 6.5\% (58 out of 894) of collected antimalarial medicines were found to be diverted, comprising 2.4\% (5/210) of medicines collected in 2007 from six African cities, all of which were artemisinin-based combination therapies (ACTs); 2.3\% (3/129) of medicines collected in 2008 in Lagos, Nigeria, two of which were ACTs; and 9\% (50/555) of medicines collected in 2010 in 10 African cities, 35 of which were ACTs. ACT was by far the most diverted treatment in this study: $15.6 \%(5 / 32)$ of ACTs collected in 2007, and 30.7\% (35/114) of ACTs collected in 2010.

Conclusion: The number of diverted ACTs over the 33 months covered by this study is probably related to the laudable provision of vast amounts of donated or low-priced ACTs across African nations and the actual increase in diversion of these medicines into the private sector. The small sample sizes in this study might exaggerate any problem, but a potentially serious problem may well exist. To the extent that diversion of medicines exacerbates stock-outs, this is a public health problem, and a perversion of donor intent, but there are other possible harms of diversion, such as increased trade in counterfeit, and expired and otherwise substandard medicines.

Keywords: artemisinin-based combination therapy (ACT), Africa, malaria, public sector

\section{Introduction}

In October and November 2007, antimalarial medicines were collected from six cities in Africa with the intent of performing a basic quality assessment of medicines available in the private sector, following the protocol established by the Global Pharma Health Fund e.V. Minilab ${ }^{\circledR}$, which has been adopted by branches of the United States and Nigerian Governments, amongst others. However, in preparing the resulting publication, ${ }^{1}$ an unexpected observation was made: some public sector medicines had been diverted to private markets. That is, medicines intended to be dispensed free of charge in public health facilities, which may have been donated by countries or manufacturers as part of aid programs, or sold at heavy discounts, were bought by researchers at varying market rates in the private sector. 
The presence of illegally diverted medicines occurs in many markets where government health workers illegally sell "public sector drugs to retail shops". ${ }^{2}$ Indeed, diversion of antimalarial medicines has been seen across numerous African markets, including Nigeria, Central African Republic, Senegal, Zambia, and Tanzania. ${ }^{2}$

Medicine diversion can lead to stock-outs in the public sector, which can have devastating effects in countries with high burdens of disease. In 2008, two years after Kenya adopted artemisinin-based combination therapy (ACT) as its first-line malaria treatment, it experienced wide stock-outs requiring intervention by the President's Malaria Initiative (PMI). ${ }^{3}$ In 2009, the Global Fund's Office of the Inspector General (OIG) reported stock-outs of ACTs for adults in Tanzania. ${ }^{4}$ Uganda has also experienced stock-outs of ACTs. ${ }^{5}$ The successful procurement and distribution of antimalarial medicines is a matter of life and death, and in countries with perennial malaria transmission, medicines must always be available.

The goal of this study was to assess the numbers of diverted antimalarial medicines from several samplings, which took place from late 2007 to early 2010 in 11 African cities, and to discuss possible causes.

\section{Materials and methods}

A total of 894 samples of antimalarial medicines were collected by local nationals from randomly selected private pharmacies in 11 African cities from late 2007 to early 2010. 210 samples were collected in October and November 2007 from pharmacies in Accra (Ghana), Nairobi (Kenya), Dar es Salaam (Tanzania), Kampala (Uganda), Kigali (Rwanda), and Lagos (Nigeria). ${ }^{1}$ Subsequent samplings took place in December 2008 and in January, February, and June 2010 using the same protocol as the 2007 sampling: 129 samples were collected in 2008 in Lagos (Nigeria); 555 samples were collected in 2010 from Lagos (Nigeria), Accra (Ghana), Addis Ababa (Ethiopia), Cairo (Egypt), Luanda (Angola), Lubumbashi (Democratic Republic of the Congo), Lusaka (Zambia), Kampala (Uganda), Nairobi (Kenya), and Dar es Salaam (Tanzania). Study agents posed as customers and purchased a sample lot of available antimalarial tablet formulations, with the exception of chloroquine, to include: sulphadoxine-pyrimethamine (SP), amodiaquine, mefloquine, artemisinin monotherapies and ACTs. All medicines were available without a prescription, and treatment packs were in the manufacturer's original packaging.

All medicines were visually inspected for correct labeling, packaging, and dosage form to detect crude counterfeits, in line with the Global Pharma Health Fund e.V. Minilab ${ }^{\circledR}$ protocol. ${ }^{6}$ Packages were visually screened for apparent trademark violations or other obvious labeling infractions, as well as for any oddities, such as manufacturing dates listed after medicine expiry dates. In this study, medicines were also inspected to determine whether they had been diverted. This study defines diverted medicines as those medicines intended to be dispensed in public health facilities free of charge or at discounted rates, but which are found on sale at varying market rates in the private sector. Packages were inspected for indications that they originated in the public sector; the medicines were in packaging that was limited to the public sector, or the packaging indicated that it was for distribution by a particular national public sector/ministry of health only (eg, in Kenya, public sector medicine packaging includes "GoK MoH; Not for Sale", and in Uganda, public sector medicine packaging includes "Property of the Government of Uganda"). In some cases, batch numbers were confirmed with the apparent manufacturer. It should be noted that while visual inspection can detect medicine diversion, there may be diverted medicines which cannot be identified using this method and therefore would not have been identified in this study.

Note that for some medicines, the labeling was in languages inappropriate for the location of purchase (eg, French packaging in English-speaking Ghana, or English packaging in French-speaking Democratic Republic of the Congo). Although many of these medicines may have been diverted, they were not considered diverted for this reason alone many of these medicines contained informational inserts which included the correct language for the location.

\section{Results}

Overall, 6.5\% (58 out of 894) of collected antimalarial medicines were diverted (see Table 1). In most instances, as determined by visual inspection, the medicines had been diverted across at least one national border, and in some cases, the manufacturer was contacted for confirmation. Of the 58 diverted medicines, the origin could be established for 30 samples: 10 were from Tanzania, eight were from Kenya, five were from Uganda, four were from Zambia, two were from Nigeria, and one was from Mozambique.

While very few of the 210 samples collected in 2007 (5, or $2.4 \%$ ) had been diverted, all five were of the best malaria treatment available, ACT ( 5 of $32 \mathrm{ACTs}$, or $15.6 \%$ ). At the time of collection, none of the medicines procured in Accra or Lagos, which included 15 ACTs, were diverted; however, two samples bought in Nairobi, Kenya, had originally been 
Table I Diverted medicines ${ }^{\mathrm{a}}$

\begin{tabular}{|c|c|c|c|c|}
\hline Sampling & Older therapies $^{b}$ & Artemisinin monotherapies & ACTs & TOTAL \\
\hline Accra 2007 & $0 \%(0 / \mid 3)$ & $0 \%(0 / 16)$ & $0 \%(0 / 8)$ & $0 \%(0 / 37)$ \\
\hline Nairobi 2007 & $0 \%(0 / 24)$ & $0 \%(0 / 14)$ & $50 \%(2 / 4)$ & $4.8 \%(2 / 42)$ \\
\hline Dar es Salaam 2007 & $0 \%(0 / 16)$ & $0 \%(0 / 17)$ & $0 \%(0 / 1)$ & $0 \%(0 / 34)$ \\
\hline Kampala 2007 & $0 \%(0 / 29)$ & $0 \%(0 / 28)$ & $0 \%(0 / 9)$ & $0 \%(0 / 66)$ \\
\hline Kigali 2007 & $0 \%(0 / 6)$ & $0 / 0$ & $100 \%(3 / 3)$ & $33.3 \%(3 / 9)$ \\
\hline Lagos 2007 & $0 \%(0 / 8)$ & $0 \%(0 / 7)$ & $0 \%(0 / 7)$ & $0 \%(0 / 22)$ \\
\hline Lagos 2008 & $1.7 \%(1 / 59)$ & $0 \%(0 / 65)$ & $40 \%(2 / 5)$ & $2.3 \%(3 / 129)$ \\
\hline Accra 2010 & $0 \%(0 / 23)$ & $0 \%(0 / 24)$ & $10 \%(1 / 10)$ & $1.8 \%(1 / 57)$ \\
\hline Lagos 2010 & $10 \%(3 / 30)$ & $0 \%(0 / 47)$ & $52.9 \%(9 / 17)$ & $12.8 \%(12 / 94)$ \\
\hline Addis Ababa 2010 & $0 \%(0 / 20)$ & $0 \%(0 / 16)$ & $33.3 \%(2 / 6)$ & $4.8 \%(2 / 42)$ \\
\hline Cairo 2010 & $0 \%(0 / 25)$ & $0 \%(0 / 19)$ & $20 \%(2 / 10)$ & $3.7 \%(2 / 54)$ \\
\hline Luanda 2010 & $10 \%(2 / 20)$ & $0 \%(0 / 17)$ & $25 \%(2 / 8)$ & $8.9 \%(4 / 45)$ \\
\hline Lubumbashi 2010 & $26.3 \%(5 / 19)$ & $0 \%(0 / 14)$ & $50 \%(3 / 6)$ & $20.5 \%(8 / 39)$ \\
\hline Lusaka 2010 & $6.5 \%(2 / 31)$ & $0 \%(0 / 2 I)$ & $0 \%(0 / 9)$ & $3.3 \%(2 / 61)$ \\
\hline Kampala 2010 & $7.4 \%(2 / 27)$ & $0 \%(0 / 18)$ & $35.3 \%(6 / 17)$ & $12.9 \%(8 / 62)$ \\
\hline Nairobi 2010 & $4.3 \%(1 / 23)$ & $0 \%(0 / 19)$ & $37.5 \%(6 / 16)$ & $12.1 \%(7 / 58)$ \\
\hline Dar es Salaam 2010 & $0 \%(0 / I 2)$ & $0 \%(0 / 16)$ & $26.7 \%(4 / 15)$ & $9.3 \%(4 / 43)$ \\
\hline TOTAL & $4.2 \%(16 / 385)$ & $0 \%(0 / 358)$ & $27.8 \%(42 / 151)$ & $6.5 \%(58 / 894)$ \\
\hline
\end{tabular}

Notes: aPercentages are supported by number of samples diverted/total samples collected; 'bncludes amodiaquine, mefloquine or sulphadoxine-pyrimethamine. Abbreviation: ACTs, artemisinin-based combination therapies.

donated to the Nigerian Government, and three samples bought in Kigali, Rwanda, were from batches that had been donated to eight other African governments, one of which was Rwanda. Recent samplings from Accra and Lagos have shown diverted medicines in these markets. It is possible that some countries' health departments allow the diversion of public sector medicines, where governments are unable to distribute medicines to where they are required.

In December 2008, 129 antimalarial medicines were collected in Lagos, Nigeria, of which three samples (2.3\%) were diverted - two of which were ACTs. In February 2010, 151 antimalarial medicines were collected in the cities of Accra and Lagos. ${ }^{7}$ Thirteen samples (8.6\%) were diverted, 10 out of 27 samples of ACTs (37\%) were diverted - most of these ACTs ( 6 out of 10) came from Tanzania. An additional 404 antimalarial medicines were collected from eight other African cities in January, February, and June 2010, including repeats of cities sampled in 2007. Thirty-seven samples (9.2\%) were found to be diverted, 25 of which were ACTs.

ACT was by far the most diverted treatment in this study ( $27.8 \%$ or 42 out of 151$)$. None of the 358 samples of artemisinin monotherapies were diverted (although 27 were in packaging with inappropriate languages for the location in which they were found), and 4.2\% (16 out of 385) of older therapies were diverted. In the 2007 sampling, five of 32 ACTs (15.6\%) were found to be diverted. Ignoring the one sampling in 2008, which was large in total size but included only a few ACTs, the sampling in 2010 found 35 of 114 ACTs (30.7\%) diverted, none of which were from countries where diversion of public sector stocks is thought to be unofficially allowed. In the 2007 sampling, ACT was the only treatment diverted. In the 2010 sampling, 15 samples of older therapies, all of which were SP, were also diverted (3.4\%, or 15 out of 441 samples of non-ACTs), but still far fewer than the number of diverted ACTs.

Two final results of interest were that the average shelf-life left for diverted ACTs (3.45 months) was noticeably shorter than the shelf-life left of the nondiverted ACTs (11.07 months), and the modal price charged for diverted ACTs was noticeably lower, roughly US\$2.30 per treatment, than the nondiverted ACTs, roughly US $\$ 4.20$ per treatment.

\section{Discussion}

The number of diverted ACTs over the roughly 33 months covered by this study is probably related to the laudable provision of vast amounts of donated or low-priced ACTs across African nations, and the actual increase in diversion of these medicines into the private sector. Of course, the small sample sizes in this study may exaggerate any problem, but if the results are replicated in larger samplings, a potentially serious problem exists.

According to an article published in Al Jazeera, Dr Stephen Malinga, the Ugandan Health Minister, suggests local officials are stealing medicines and selling them onto the black market. ${ }^{8}$ Investigators believe central officials in Kenya, Uganda, and Tanzania are also involved in the sale of nearly expired and expired medicines. Once a medicine is deemed too old to sell, it is supposed to be destroyed; however, there 
is little evidence when a medicine has actually been destroyed, providing cover for officials intent on diverting medicines for personal profit instead. This possible pathway by which nearly expired medicines are stolen and diverted is supported by the data gathered in this study - diverted ACTs have a noticeably shorter shelf-life than nondiverted equivalent medicines. An alternative explanation is that the illegal transit of these medicines takes numerous months.

There are many possible reasons that ACTs may be diverted more than other malaria treatments - some are related to ease of observation, others are a matter of fact based on prices and policy. Only ACTs are routinely labeled or packaged differently for the public sector, in order to make identification easier, thereby making it easier to spot diverted ACTs. Furthermore, ACTs are the recommended treatment for malaria and are almost solely funded by donors. There is therefore a ready supply, perhaps 100 million treatments for African countries alone, of medicines which can sell for over US\$5 per treatment, and perhaps as high as US\$12 per treatment in the private sector.

\section{The public sector}

The Global Fund to Fight AIDS, Tuberculosis and Malaria (Global Fund) is the single largest source of funding for ACTs. ${ }^{9}$ As of June 2010, Global Fund-supported programs have delivered 142.4 million malaria treatments; ${ }^{10} 90$ million courses for sub-Saharan Africa. ${ }^{11}$ The overwhelming majority of medicines bought for malaria will be ACTs, although it is not broken down precisely in available documents. The United States Agency for International Development (USAID)-led PMI purchased approximately 29 million ACT treatments in 2009 alone. This puts the total public sector market at over 100 million ACTs.

With so many medicines being procured for the public sector, some are bound to be diverted, unless there is careful oversight over procurement systems and medicines distribution. The OIG Audit Report on Global Fund Grants to Tanzania ${ }^{4}$ noted US\$819,000 in missing ACTs in 2007. The local fund agent (LFA) of the Round 4 grant attributed the missing ACTs to "weaknesses and capacity problems" with the Medical Stores Department's computerized inventory management system. It should be noted that according to the report, the specific missing medicines were not directly funded with Global Fund resources; although if the capacity problems are significant, any medicines (donated, procured locally, or through international tender) are at risk of theft and diversion.

In fact, a recent Global Fund OIG Review of oversight of Grant Procurement and Supply Chain Management arrangements points out several risks emerging to Global
Fund programs, including the following: "Quality assured health products imported using Global Fund funds may be exchanged for inferior or counterfeit products which are then distributed to the intended recipients of the grants. The quality assured health products are then sold in commercial centers in the country or exported to neighbouring countries". ${ }^{12}$

In 2007, the US Government Accountability Office reported that the Global Fund has "limited access to the information it needs to manage and oversee LFAs because it does not require systematic assessments of LFAs' performance". ${ }^{13}$ Numerous sources have raised "concerns about the quality of grant monitoring and reporting" provided by the Global Fund's LFAs, particularly on "their ability to assess and verify recipients' procurement capacity and program implementation". ${ }^{13}$

Since January 2008, Angola has lost over US\$642,000 in diverted USAID-funded antimalarial medicines, limiting the effectiveness of its PMI program. ${ }^{14}$ The loss was the result of four thefts of the procured ACT meant to treat over 534,000 people with malaria. According to an audit report by the Office of Inspector General, the thefts occurred because "USAID/Angola did not ensure a quick and proper delivery of the drug from the airports and because it relied on a distribution system with significant control weaknesses managed by the Government of Angola". ${ }^{14}$ The fourth thefts, in May 2009, occurred while the medicines were under the control of the Angolan Ministry of Health and after enhanced control procedures had been put in place.

There have also been recorded instances of medicine diversion apart from the Global Fund and PMI. In Uganda and Cameroon, for example, it was reported that government health workers sold public sector antimalarial medicines to retail shops. ${ }^{2}$ In April 2010, Uganda's New Vision newspaper reported that antimalarial medicines donated by the Chinese government meant for referral hospitals were diverted to a private company, schools, and individuals. ${ }^{15}$ The medicines had allegedly been unlawfully requisitioned by three senior Ministry of Health officials in charge of the malaria program in Uganda; they have since been charged with corruption and mismanagement of the medicines. ${ }^{16}$

\section{Expired medicines}

Chaotic management of healthcare services and supplies in many countries leaves both caregivers and patients at risk. The Kenyan public health system is burdened by a budgetary crisis caused by an overhang of unpaid bills to suppliers from 2008-2009. The National Nurses Association of Kenya fears that a proposal to resolve the latest stock-out by sourcing new 
local suppliers leaves doubt that the quality of supplies can be maintained, and may result in patients receiving expired medicines. $^{17}$

Expired medicines are a notorious problem in Uganda, as is freely admitted by the General Manager of the National Medical Stores, Mr Moses Kamabare, in Uganda's Daily Monitor. ${ }^{18} \mathrm{Mr}$ Kamabare points to mismanagement at district health facilities, where stock either runs out or expires on shelves because staff is unable to anticipate demand. Furthermore, while it is the responsibility of the National Drug Authority to monitor destruction of expired stock, there is no system in place, nor any budget available, to separate, load or transport expired stock to an approved incineration facility. Unfortunately, the types of problems Mr Kamabare identifies are not limited to Uganda, so it becomes easy to see how medicine theft and diversion across borders can occur.

\section{Effects of medicine diversion}

To the extent that diversion of medicines exacerbates stock-outs, this is a public health problem, and a perversion of donor intent, but are there other possible harms of diversion? One could argue that a good quality medicine diverted from the public sector is at least available for sale in the private sector, perhaps a part of the private sector which was not receiving newer types of medicines, such as ACTs. Even if criminals profit handsomely from diversion, at least from a public health standpoint, assuming the medicine is not degraded in transit, a diverted medicine is available for purchase.

If the figures in this study are more broadly indicative then the problem is significant. First, and in the short-run most important, if diversion is happening, it partially explains the increase in reported stock-outs, and is a predictor of more to come; for this reason alone it should be combated. But there are longer-term implications as well.

As is beginning to be documented, ${ }^{19}$ what starts as trade in stolen smuggled goods (of good quality), over time can become trade in counterfeit, expired, and otherwise substandard medicines. Traders start selling real medicines across borders but over time adapt into the more lucrative business of recycling packaging, buying pill and blister pack production equipment, and then making nonbioequivalent medicines. Over time, since these illegal players can always undercut the legitimate market, they can increase market share, undermining legitimate delivery.

Medicine diversion is not purely the problem of stock-outs and limited profits for businesses; it is a concern for all who want sustainable procurement systems and access to safe medicines. If the data in this study are replicated in larger samplings, then the malaria community should respond and demand changes to the procurement systems and medicines distribution.

\section{Recommendations}

The Global Fund and PMI are to be commended for conducting and publishing proper audits, which inevitably explain any failures. It is imperative that all donors publish independent audits like those of these organizations - without them, procurement agents, government analysts, and other interested parties would remain in the dark about important problems.

Secondly, donors must require more from their recipients. For the past couple of years, PMI has utilized an end-user verification program, ${ }^{20}$ which although not foolproof, demands checks of recipients. Measurements of medicine availability, how many medicines are near expiry or expired, and other measurements of medicine distribution are demanded, which probably improves management and highlights locations where theft is more likely.

More pressure has to be applied on the recipient governments, which seem to assume theft and diversion are just costs of doing business. PMI ceased using the Angolan Government's warehouse after its donated medicines were repeatedly stolen; ${ }^{21}$ and the Global Fund has suspended grants and halted disbursements in the past to countries like Uganda ${ }^{22}$ and Zambia ${ }^{23}$ due to allegations of corruption and mismanagement of funds. Ultimately, all donors should not only be prepared to pull out of a country where medicines are stolen, but demand redress for thefts. If not, they condone and encourage bad behavior.

All donors should conduct operational research and covert medicine purchases from the private sector to monitor medicine diversion. They should work with pharmaceutical companies and local security experts to find those responsible and bring criminal penalties on them, especially those crossing borders - exporting and importing diverted medicines.

Donors should also be prepared to try new methods to limit diversion. One new public-private initiative, known as SMS for Life, is taking aim at eliminating stock-outs and improving access to essential medicines by sending weekly text messages to health facilities to collect stock levels of ACTs and rapid diagnostic tests so inventories can be closely monitored. The project significantly improved stock management and the availability of malaria medicines in a pilot in Tanzania by reducing stock-out rates in all three districts. ${ }^{24}$

\section{Conclusion}

This paper provides original evidence of medicine diversion, as well as details provided by the Offices of the Inspector 
General at both PMI and Global Fund. Unless such activities like those described above are undertaken, we predict more stock-outs and the strengthening of criminal elements in medicine distribution across Africa.

\section{Acknowledgments/disclosure}

The authors report no conflicts of interest in this work. A large number of people have helped in the collection of medicines analyzed in this study. The authors would particularly like to thank Thompson Ayodele and Franklin Cudjoe for their assistance. The authors thank the Legatum Institute and Legatum Foundation for support for this research.

\section{References}

1. Bate R, Coticelli P, Tren R, Attaran A. Antimalarial drug quality in the most severely malarious parts of Africa - a six country study. PLoS One. 2008;3(5):e2132.

2. Patouillard E, Hanson K, Goodman C. Retail sector distribution chains for malaria treatment in the developing world: a review of the literature. Malar J. 2010;9:50.

3. President's Malaria Initiative. Malaria Operational Plan (MOP) Kenya FY2009. Available from: http:/www.fightingmalaria.gov/countries/ mops/fy09/kenya_mop-fy09.pdf. Accessed Jul 2, 2010.

4. The Global Fund to Fight AIDS, Tuberculosis and Malaria. The Office of the Inspector General, Audit Report on Global Fund Grants to Tanzania. Issue Date: 10 June 2009. Available from: http:/www.theglobalfund.org/ documents/oig/Tanzania_Country_Audit_Final_Report.pdf. Accessed Jul 2, 2010.

5. Zurovac D, Tibenderana J, Nankabirwa J, et al. Malaria casemanagement under artemether-lumefantrine treatment policy in Uganda. Malar J. 2008;7:181.

6. Global Pharma Health Fund-Minilab. Manuals. Update: 2008. Available from: http://www.gphf.org/web/en/minilab/manuals.htm. Accessed Aug 18, 2010.

7. Bate R, Hess K. Anti-malarial drug quality in Lagos and Accra - a comparison of various quality assessments. Malar J. 2010; 9:157.

8. Honigsbaum M. The killing season. Al Jazeera. 2010 May 30. Available from: http://english.aljazeera.net/focus/2010/05/20105261374999817. html. Accessed Aug 18, 2010.

9. Cohen J, Singh I, O’Brien M. Predicting Global Fund grant disbursements for procurement of artemisinin-based combination therapies. Malar J. 2008;7:200.

10. The Global Fund to Fight AIDS, Tuberculosis and Malaria. Fighting AIDS, Tuberculosis and Malaria [as of June 2010]. Available from: http://www.theglobalfund.org/en/fighting/?lang=en. Accessed Jul 2, 2010.

11. The Global Fund to Fight AIDS, Tuberculosis and Malaria. Press Release, World Malaria Day: 2010 is critical year for global efforts to defeat malaria. 2010 Apr 25. Available from: http://www.theglobalfund. org/en/pressreleases/?pr=pr_100414. Accessed Jul 2, 2010.
12. The Global Fund to Fight AIDS, Tuberculosis and Malaria. The Office of the Inspector General, Review of oversight of Grant Procurement and Supply Chain Management arrangements. Issue Date: 2010 Apr 22. Available from: http://www.theglobalfund.org/documents/ oig/Review\%20of\%20oversight $\% 20$ of $\% 20$ grant $\% 20$ procurement $\% 20$ and $\% 20$ supply $\% 20$ chain $\% 20$ management $\% 20$ arrangements_TGF_ OIG_10_002.pdf. Accessed Jul 2, 2010.

13. United States Government Accountability Office. Report to Congressional Committees, Global Health, Global Fund to Fight AIDS, TB and Malaria has improved its documentation of funding decisions but needs standardized oversight expectations and assessments. May 2007. Available from: http://www.gao.gov/new.items/d07627.pdf. Accessed Jul 2, 2010.

14. US Agency for International Development. Office of Inspector General, Audit of USAID/Angola's Procurement and Distribution of Commodities Under the President's Malaria Initiative. December 21, 2009. Available from: http://www.usaid.gov/oig/public/fy10rpts/4-654-10-001-p. pdf. Accessed Jul 2, 2010.

15. Anyoli E. Witness pins officials on drug diversion. The New Vision. 2010 April 27. Available from: http://www.newvision.co.ug/ D/8/13/717754. Accessed Jul 2, 2010.

16. Anyoli E. Witness pins health ministry officials. The New Vision. 2010 April 22. Available from: http://www.newvision.co.ug/ D/8/13/717199. Accessed Jul 2, 2010.

17. Wesangula D, Marete G, Amadala B, Njagi J, Ochieng A. Acute Drug Shortage in Public Hospitals Condemns the Sick to Misery. Daily Nation. 2010 February 6. Available from: http://www.nation.co.ke/News//1056/857262/-/item/0/-/4 m614u/-/index.html. Accessed Jul 2, 2010.

18. Naturida S. National Medical Stores: Turning a new page in the handling and disbursing of medicine. Daily Monitor. 2010 Feb 25. Available from: http://www.monitor.co.ug/Magazines/Health\%20\&\%20Living//689846/868198/-/format/xhtml/-/ybdcrv/-/index.html. Accessed Jul 2, 2010.

19. Bate R. Lessons from a Syrian Drug Bust. The Wall Street Journal. 2010 April 28. Available from: http://online.wsj.com/article/SB1000142 4052748704423504575211920119322724.html. Accessed Jul 2, 2010.

20. Roll Back Malaria. PMI End Use Verification Tool. Available from: http://www.rollbackmalaria.org/toolbox/tool_PMIendUseVerification. html. Accessed Jul 2, 2010.

21. President's Malaria Initiative. Malaria Operational Plan - Year Five (FY2010) Angola. Available from: http://www.fightingmalaria.gov/ countries/mops/fy10/angola_mop-fy10.pdf. Accessed Jul 2, 2010.

22. The Global Fund to Fight AIDS, Tuberculosis and Malaria. Press Release, Global Fund Suspends Grants to Uganda. 24 August 2005. Available from: http://www.theglobalfund.org/en/pressreleases/?pr=pr_050824. Accessed Jul 2, 2010.

23. The Global Fund to Fight AIDS, Tuberculosis and Malaria. Press Release, Global Fund Confirms Freeze on Cash Disbursements to Zambia's Ministry of Health, Grants to be Transferred to UNDP. 2010 Jun 16. Available from: http://www.theglobalfund.org/en/ pressreleases/?pr=pr_100616. Accessed Jul 2, 2010.

24. Roll Back Malaria. SMS for Life Tanzania Pilot Project Report, Summary Report. Available from: http:/www.rollbackmalaria.org/docs/ SMSsummaryReport.pdf. Accessed Jul 2, 2010.
Research and Reports in Tropical Medicine

\section{Publish your work in this journal}

Research and Reports in Tropical Medicine is an international, peerreviewed, open access journal publishing original research, case reports, editorials, reviews and commentaries on all areas of tropical medicine, including: Diseases and medicine in tropical regions; Entomology; Epidemiology; Health economics issues; Infectious disease; Laboratory

\section{Dovepress}

science and new technology in tropical medicine; Parasitology; Public health medicine/health care policy in tropical regions; and Microbiology. The manuscript management system is completely online and includes a very quick and fair peer-review system. Visit http://www.dovepress. com/testimonials.php to read real quotes from published authors. 